\title{
Do inositol supplements enhance phosphatidylinositol supply and thus support endoplasmic reticulum function?
}

\author{
Robert H. Michell* \\ School of Biosciences, University of Birmingham, Edgbaston, Birmingham B15 2TT, UK \\ (Submitted 29 November 2017 - Final revision received 26 February 2018 - Accepted 14 March 2018 - First published online 3 June 2018)
}

\section{Abstract}

This review attempts to explain why consuming extra myoinositol (Ins), an essential component of membrane phospholipids, is often beneficial for patients with conditions characterised by insulin resistance, non-alcoholic fatty liver disease and endoplasmic reticulum (ER) stress. For decades we assumed that most human diets provide an adequate Ins supply, but newer evidence suggests that increasing Ins intake ameliorates several disorders, including polycystic ovary syndrome, gestational diabetes, metabolic syndrome, poor sperm development and retinopathy of prematurity. Proposed explanations often suggest functional enhancement of minor facets of Ins Biology such as insulin signalling through putative inositol-containing 'mediators', but offer no explanation for this selectivity. It is more likely that eating extra Ins corrects a deficiency of an abundant Ins-containing cell constituent, probably phosphatidylinositol (PtdIns). Much of a cell's PtdIns is in ER membranes, and an increase in ER membrane synthesis, enhancing the ER's functional capacity, is often an important part of cell responses to ER stress. This review: (a) reinterprets historical information on Ins deficiency as describing a set of events involving a failure of cells adequately to adapt to ER stress; (b) proposes that in the conditions that respond to dietary Ins there is an overstretching of Ins reserves that limits the stressed ER's ability to make the 'extra' PtdIns needed for ER membrane expansion; and (c) suggests that eating Ins supplements increases the Ins supply to Ins-deficient and ER-stressed cells, allowing them to make more PtdIns and to expand the ER membrane system and sustain ER functions.

Key words: Insulin resistance: Gestational diabetes mellitus: Polycystic ovarian syndrome: Spermatogenesis: Hypothyroidism: Nonalcoholic fatty liver disease: Endoplasmic reticulum stress

Mammalian cells use myoinositol (Ins), a polyol that used also to be known as vitamin B8, as the core constituent of eight Ins phospholipids (the phosphoinositides, see Box 1), of many Ins polyphosphates and of the glycerophosphoinositol-based (GPI) anchors of cell surface proteins ${ }^{(1) \S}$. It is quite difficult to make mammals overtly Ins-deficient, except under nutritionally extreme conditions - and then a major symptom is fat accumulation in the liver and/or intestine. It is now commonly assumed that a normal diet plus some endogenous synthesis usually provides us (and other animals) with an adequate supply of Ins.

However, recent evidence suggests that consuming extra Ins as a dietary supplement can be beneficial in a variety of human conditions, particularly those characterised by adiposity, hyperglycaemia and insulin resistance. These conditions include polycystic ovary syndrome (PCOS), gestational diabetes mellitus (GDM) and metabolic syndrome (MetS). Other possible benefits of Ins supplements include better sperm development and motility, improved ovarian follicle and embryo development, suppression of diabetes-induced and folate-resistant developmental birth defects, and amelioration of respiratory distress syndrome and retinopathy in premature infants (see references $2-5$, for reviews). At least some of these suggested clinical benefits will probably become more firmly established once larger trials have been conducted.

The most prevalent hypothesis in discussions of these exciting observations has been that eating extra Ins might support the formation and actions of proposed, but controversial, 'mediators' of insulin action that contain inositols as constituents ${ }^{(2,6)}$.

\footnotetext{
$\$$ Abbreviations for myoinositol and its derivatives: Ins is the accepted abbreviation for myoinositol, both free and in chemical combination (see http:// www.sbcs.qmul.ac.uk/iupac/cyclitol/myo.html) and is here used in: ArcIns, archaetidylinositol (the most common archaeal lipid with an Ins1P headgroup); Ins, myoinositol; Ins $1 P$, Ins 1-phosphate; Ins $P_{6}$, Ins bexakisphosphate (phytic acid); and Ptdins, phosphatidylinositol. Other inositol isomers are named or abbreviated individually (see below). Ins is sometimes used elsewhere as an informal abbreviation for insulin, but to avoid confusion this review will always spell out insulin in full.

Other abbreviations: ATF6, activating transcription factor-6; CCT, CTP:phosphocholine cytidylyltransferase; CDIPT, CDP-DG inositol phosphotransferase (三 PIS); CDP-DG, cytidine diphosphate diacylglycerol; DCI, D-chiro-inositol; DM2, Type 2 diabetes mellitus; ER, endoplasmic reticulum; GDM, gestational diabetes mellitus; GPI, glycerophosphoinositol; IPG, inositol phosphate glycan; IRE1, inositol-requiring enzyme-1; LPIAT1, lysoPtdIns acyltransferase-1 (三 MBOAT7); MetS, metabolic syndrome; MIOX, myoinositol oxidase; MIPS, myoinositol 3-phosphate synthase; NAFLD, non-alcoholic fatty liver disease; PCOS, polycystic ovarian syndrome; PERK, PKR-like ER kinase; PI3K-I, Type I phosphoinositide 3-kinase; PIS, PtdIns synthase (三 CDIPT); PM, plasma membrane; PPIn, polyphosphoinositide; PtdCho, phosphatidylcholine; PtdEtn, phosphatidylethanolamine; PtdOH, phosphatidate; PtdSer, phosphatidylserine; TAFLD, toxicantassociated fatty liver disease; UPR, unfolded protein response.
} 


\section{Box 1. Inositols and inositol phospholipids in eukaryotes: summary}

The inositols are nine stereoisomeric hexahydroxycyclohexanes: saturated six-carbon rings with a hydroxyl group attached to each carbon.

Myoinositol is the predominant inositol in Nature. It is abbreviated as Ins unless its full name is needed to distinguish it from another inositol isomer, such as D-chiro-inositol (DCI) (see the footnote on p. 1 for a more detailed discussion of abbreviations).

Phosphatidylinositol (PtdIns) is much the most abundant membrane inositol-containing phospholipid (phosphoinositide) throughout the cell. It is made at the cytoplasmic face of the endoplasmic reticulum (ER), where much of it stays, by PtdIns synthase (abbreviated as PIS or CDIPT).

Phosphoinositide kinases in the non-ER membrane compartments of the cells of mammals and other metazoan eukaryotes phosphorylate some of their PtdIns to form small amounts of seven polyphosphoinositides (PPIn): these are three isomeric PtdIns monophosphates (PtdIns3P, PtdIns $4 P$ and PtdIns5 $P$ ), three PtdIns bisphosphates $\quad\left(\operatorname{PtdIns}(3,4) P_{2}, \quad \operatorname{PtdIns}(3,5) P_{2}\right.$ and PtdIns $\left.(4,5) P_{2}\right)$ and one PtdIns trisphosphate (PtdIns $\left.(3,4,5) P_{3}\right)$ (see the text for references).

However, there is no direct evidence in support of this idea, and none of these discussions has attempted to explain how eating quite a lot of Ins - maybe enough to approximately double the usual dietary intake - might selectively amplify this minor and ill-understood facet of the Biology of Ins.

It seems more likely that the extra dietary Ins corrects a mild systemic Ins deficiency that restricts the production of an abundant and essential Ins-containing cell component, and the obvious candidate is phosphatidylinositol (PtdIns), a ubiquitous constituent of eukaryotic cell membranes. If this is correct then the central problem becomes to discover how allowing stressed tissues to make more PtdIns contributes to their health?

This review attempts to answer this question by:

(1) giving a snapshot of the diverse biological functions of Ins and its derivatives;

(2) summarising the endogenously synthesised and dietary sources of Ins;

(3) looking back to early work on Ins deficiency in mammals and considering how recent work on endoplasmic reticulum (ER) stress might help us to understand it better;

(4) summarising the evidence that Ins supplements ameliorate several conditions in which overweight, insulin resistance, hyperglycaemia and ER stress often coexist; and

(5) considering what mechanisms might underlie these benefits, and how experimentally to explore them.

These considerations lead to the conclusion that we should in future focus our attention on understanding when and why the ER sometimes needs to increase its production of PtdIns, the cell's most abundant and least studied phosphoinositide, especially when a cell's homeostatic adjustment to ER stress demands an increase in the rate of ER membrane synthesis - and how limitation of the Ins supply may prejudice this response.

\section{Ins functions and supply}

During the last four decades it has been recognised that PtdIns and its seven polyphosphorylated derivatives (the polyphosphoinositides (PPIn)) (see Box 1 and Fig. 1) have many essential functions, particularly in transmembrane signalling, in 'labelling' the identities of membrane compartments and in membrane trafficking ${ }^{(1,7-10)}$. Ins is also the precursor to a plethora of water-soluble Ins polyphosphates, only a few of which have understood functions ${ }^{(1-14)}$. And some PtdIns is channelled to the luminal face of the ER and incorporated into PtdIns glycan structures that will form the 'GPI anchors' that tether many proteins onto the external surfaces of eukaryotic cells ${ }^{(15,16)}$. Alongside these well-established functions there is 30 years of less than conclusive evidence, to be discussed below, that insulin receptor stimulation might activate a phospholipase that liberates inositol phosphate glycan molecule(s) (IPGs) similar to those in GPI anchors, and that these might serve as second messengers that initiate some tissue responses to insulin.

Free Ins is the precursor of all of these molecules, and eukaryote cells get Ins from two sources. Some tissues, including brain and kidneys, and especially testes, make Ins de novo from the central metabolite D-glucose-6-phosphate by the sequential actions of myoinositol 3-phosphate synthase (MIPS, encoded in yeast by Ino1 and in humans by ISYNA1) and inositol monophosphatases (InsPases, encoded in yeast by Inm1 and Inm2, and in mammals by IMPA1 and IMPA2) ${ }^{(17)}$. Secondly, specific cation/ Ins co-transporters that use $\mathrm{Na}^{+}$or $\mathrm{H}^{+}$as co-solutes (SMIT1/ SLC5A3, SMIT2 and HMIT/SLC2A13) harvest Ins from the gut, take it into the tissues from the blood and recover it from the renal glomerular filtrate ${ }^{(18)}$. It is commonly assumed that cells use imported and locally made Ins in similar ways, but some observations suggest that this is not always the case ${ }^{(19,20)}$.

All eukaryotic cells need an Ins supply to make PtdIns and other Ins derivatives. It was discovered long ago that yeasts only survive if they can make and/or import Ins; that many mammalian celllines require an external Ins supply ${ }^{(21-23)}$; and that mammalian embryos which cannot make Ins develop abnormally, and the offspring die perinatally unless they are fed Ins from birth ${ }^{(24)}$.

Dietary Ins comes mainly from the PtdIns in plant and animal foodstuffs and from the inositol polyphosphates (mainly phytic acid; Ins $P_{6}$ ) that are abundant in many seeds. Normal human Ins intake has been estimated to be in the range $0 \cdot 25-2 \mathrm{~g} / \mathrm{d}^{(25,26)}$, but we lack precise estimates of how much of that dietary Ins we absorb. Taking Ins $P_{6}$ as an example, different raw, cooked and processed foods contain very different amounts, and it is not even agreed how much of the Ins in ingested $\operatorname{Ins} P_{6}$ is absorbed and in what form ${ }^{(27,28)}$. Recent studies suggest that the gut cannot absorb intact Ins $P_{6}^{(29)}$, so it is likely that dietary Ins $P_{6}$ must be fully dephosphorylated before Ins transporters can absorb it from the gut.

Given this background, it is somewhat surprising that a growing body of information - which is discussed below and 

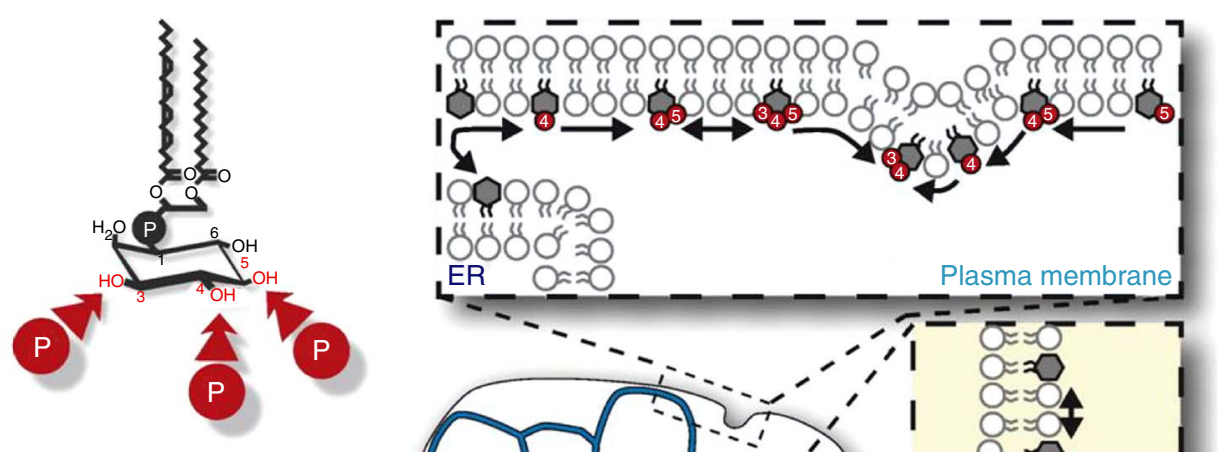

Fig. 1. The distribution, relative amounts and interconversions of Ins phospholipids in a generalized mammalian cell. This figure is reproduced, with permission, from reference (10), but the legend is mine. This generalised representation of a cell summarizes the distributions and relative quantities of the various organelles and of phosphatidylinositol (Ptdlns) and the various polyphosphoinositides (PPIn) in these membrane subcompartments of eukaryote cells. The relative areas of membrane and volumes of the various organelle compartments, and thus their relative contents of membrane lipids (including Ptdlns and PPIn) will vary substantially between cell-types. Important points to note include the following: (1) in many cells the endoplasmic reticulum (ER)/nuclear envelope continuum (the blue reticulum in this image) usually contains a larger proportion of a cell's membranes than other organelle systems; (2) Ptdlns is made in the ER (blue) and is the only phosphoinositide there (except maybe for transient traces of Ptdlns4P); (3) Ptdlns is a structural lipid that is distributed amongst all cell membranes (with less in the mitochondrial inner membrane), and is also the substrate for synthesis and turnover of all of the compartment-specific PPIn that are in the various non-ER and nonmitochondrial membrane systems (images of which are schematically expanded in the coloured boxes in this diagram).

summarised in Table 1 - suggests that some people get substantial health benefits if they supplement their normal diets with an extra $1-4 \mathrm{~g}$ of Ins/d (see references 2-5, 30-32, for reviews). The most notable effects include an amelioration of insulin resistance and of the related metabolic problems that characterise PCOS, GDM, MetS and Type 2 diabetes mellitus (DM2). The text that follows: (a) briefly summarises a number of the studies that suggest that dietary supplementation with Ins is beneficial to humans and to relevant rodent models; (b) discusses the suggested interpretations of these studies; (c) offers a novel interpretation of these striking findings; and (d) suggests some experimental approaches that might help us to understand these findings and to explain the health benefits of this inexpensive and safe nutritional supplement.

First, though, three other topics need to be briefly discussed as background: a possible reinterpretation of studies - both older and more recent - of Ins deficiency in mammals and other metazoans; the roles of various Ins derivatives in insulin signalling; and the long history of relationships between diabetes and Ins metabolism.

Ins deficiency provokes the development of steatoses (and ER stress?)

One of the most notable early observations was that dietary Ins deficiency - usually in rats or gerbils - causes an Ins-reversible fat accumulation (steatosis) in the liver and/or the intestinal mucosa. This is most striking when withdrawal of Ins from the diet is combined either with a diet rich in saturated fat or with the nutrient stress of lactation (when the mother is secreting lots of Ins into her milk for the suckling offspring) ${ }^{(22,26,33)}$. Dietary Ins supplementation sometimes also ameliorates fatty livers caused by other metabolic stresses, such as choline deficiency $^{(26)}$. One unifying defect in these steatoses is a failure by the Ins-deficient organs efficiently to package and secrete the TAG-rich lipoproteins that they make (VLDL in hepatocytes and chylomicra in enterocytes). It has been assumed that a cellular deficit of PtdIns (and maybe of PtdIns-derived PPIn) somehow causes these symptoms - and during Ins deficiency in gerbils the PtdIns content of microsomal membranes from the intestinal mucosa was Ins-reversibly decreased by more than one-half ${ }^{(34)}$.

The underlying mechanisms of these steatoses have never been fully understood, and by the late 1980s there was a widespread belief that a combination of endogenous Ins synthesis and a balanced diet provides an adequate supply of Ins to most mammals, including humans ${ }^{(2,22,25,26)}$. As a result, most researchers turned their attention to problems that seemed more exciting.

More recently, it has been recognised that transient or sustained hepatic steatosis - which may or may not indicate incipient or overt pathology - occurs in many situations of metabolic imbalance, and this has taken centre stage under a new name: non-alcoholic fatty liver disease (NAFLD) ${ }^{(35,36)}$. A variety of metabolic stresses can provoke and/or are closely associated with 
NAFLD (or TAFLD, its Toxicant-Associated equivalent ${ }^{(37)}$ ). These conditions include central obesity, saturated fat feeding and viral hepatitis, as well as toxic insults such as carbon tetrachloride poisoning or tunicamycin inhibition of protein glycosylation. NAFLD is common in patients with several of the conditions for which dietary Ins supplements are now promoted, including PCOS, GDM, MetS and DM2 $2^{(36,38-40)}$

NAFLD is one of the commonest hepatic accompaniments of the widespread unfolded protein response (UPR) that is evoked in all eukaryotes by diverse stressors that cause accumulation of incompletely folded proteins within the ER - a situation that is known generically as 'ER stress'. Cellular responses to ER stress, which in the liver often include fat accumulation in hepatocytes, are orchestrated by a complex set of coordinated controls, the master regulators of which are three transmembrane ER proteins: IRE1 (Inositol-Requiring Enzyme-1), which is present in all eukaryotes (mammals have two: IRE1 $\alpha$ and IRE1 $\beta$ ); PERK (PKR-like ER Kinase), which is restricted to metazoans; and ATF6 (Activating Transcription Factor-6), which is also restricted to metazoans (mammals have two: ATF6 $\alpha$ and ATF6 $\beta$ ) (see references 41-47 and the later discussion). The ubiquitous ER stress sensor IRE1 is a dual-activity protein kinase and endoribonuclease that is central to responses provoked by diverse stressors, but its name is a confusing hangover from the fact that it was first identified as a key player in the responses of yeast to changes in external Ins supply ${ }^{(23,48)}$.

Three more recent studies have shown that interfering with the PtdIns supply in cells in other ways can provoke steatoses that have some similarities to those seen in classical studies of Ins deficiency - and which again resemble the NAFLD that is associated with ER stress and the UPR.

First, Alb et al. ${ }^{(49,50)}$ observed that reducing or abolishing rats' ability to make $\operatorname{PITP} \alpha$, a cytosolic phospholipid exchange protein that may have a role in distributing PtdIns around cells, provokes hepatic and intestinal steatoses similar to those provoked by Ins deficiency ${ }^{(51)}$

Secondly, ablation in zebrafish embryos of the gene encoding PtdIns synthase (PIS, also known as CDP-diacylglycerol-inositol phosphotransferase (CDIPT)) is lethal in 5-6 days. But these PISnull embryos develop a fatty liver during the final developmental days before they die. It seems that they initially import maternally provided PtdIns from yolk, and this allows them to develop fairly normally for up to $\sim 4$ days, but when this runs out they briefly develop an acute PtdIns deficiency and a fatty liver - in which a suite of genes indicative of ER stress is turned on - and then they die. And treatment of wild-type embryos with tunicamycin, an inhibitor that induces ER stress by preventing the glycosylation and correct folding of nascent proteins within the ER, produces remarkably similar effects ${ }^{(52)}$. These PIS-null embryos also develop an intestinal mucosal pathology that partially mimics inflammatory bowel disease, and which appears to be initiated by disruption of the ER architecture in enterocytes ${ }^{(53)}$.

Third, Drosophila larvae that lack or have reduced levels of PIS or of CDP-diacylglycerol synthase (which makes the immediate lipid precursor of PtdIns) develop only partially and are non-viable. Many of their PtdIns-deprived tissues stay abnormally small during their abortive development and display abnormal intracellular accumulations of fat droplets ${ }^{(54)}$.
Considered as a whole, these results suggest that: (a) the liver and intestinal steatoses that were recognised many decades ago as hallmarks of Ins deficiency were early examples of NAFLD and its intestinal equivalent; and (b) these steatoses were probably unrecognised consequences of the fact that a cellular deficit of Ins, and thus of PtdIns, stresses the ER and activates the protective/homeostatic ER stress pathways. These steatoses are particularly striking accompaniments of ER stress in hepatocytes and enterocytes, both of which are cells whose ER's major tasks include the synthesis and assembly of secretory lipoproteins, but the Drosophila observations also suggest that the stress of PtdIns depletion may provoke fatty infiltration of other tissues ${ }^{(54)}$. And the Ins-reversible loss in Ins-deficient gerbils $^{(34)}$ of much of the enterocyte's alkaline phosphatase - a GPI-anchored protein that is normally made by the ER and trafficked to the exterior of the brush border membrane that faces the gut lumen - was probably another early indication of ER malfunction provoked by PtdIns deficiency.

It therefore seems likely that ER stress is widespread in the tissues of overtly Ins-deficient animals, especially in those tissues in which cells are subjected to fluctuating demands for protein secretion and/or for ER expansion (such as the insulinsecreting $\beta$-cells of pancreatic islets of Langerhans ${ }^{(55)}$ ). The final sections of this review will suggest a novel explanation of the benefits of dietary Ins supplements that is based on the idea: that the ER must manufacture new membrane phospholipids, including PtdIns, whenever a cell needs to expand its ER membrane area as an element of its response to ER stress; that a mild global Ins deficiency often interferes with this process in metabolic diseases such as PCOS and GDM; and that Ins supplements can relieve this deficiency.

\section{Ins derivatives in insulin signalling, and the inositol derivatives used as dietary supplements}

Insulin resistance is one of the physiological features of many of the conditions for which dietary Ins supplements are being promoted $^{(2)}$; and Ins-containing molecules have at least one, and maybe two or three, role(s) in insulin signalling.

First, the predominant mode of insulin receptor signalling into cells is via receptor-catalysed tyrosine phosphorylation of insulin receptor substrate-1 (IRS-1), which then activates Type I PPIn 3-kinase (PI3K-I) (and other targets). Activated PI3K-I converts a small amount of plasma membrane PtdIns $(4,5) P_{2}$ into PtdIns $(3,4,5) P_{3}$, and this $\operatorname{PtdIns}(3,4,5) P_{3}$ recruits and regulates multiple effector proteins that control diverse cell responses (reviewed in reference 56).

Secondly, soluble Ins-containing second messengers (or 'mediators') might mediate some of the actions of insulin. A decade before insulin-stimulated PI3K-I signalling was discovered, Joseph Larner's laboratory offered evidence that insulin-stimulated skeletal muscle makes a soluble 'mediator' of insulin action ${ }^{(57)}$. Subsequent work has suggested that: (a) two such mediators (named IPG-A and IPG-B) might each control a different subset of tissue-specific responses to insulin; (b) each IPG contains an inositol (myoinositol in IPG-A and D-chiro-inositol (DCI) in IPG-B); and (c) these IPGs are structurally related to, and might be derived from, the GPI anchors of 
cell surface proteins ${ }^{(58-60)}$. However, different laboratories have reported very different biological effects even when working with similar molecules ${ }^{(59,60)}$, and the status of these ideas remains uncertain after almost 40 years.

Despite these uncertainties, the idea that eating substantial dietary supplements of Ins may augment insulin signalling through IPGs has dominated many recent discussions ${ }^{(2,4,6)}$. This emphasis has been especially prevalent in studies that have focussed on supplements consisting of Ins/DCI combinations, of DCI alone or of plant-derived DCI derivatives such as pinitol (3-O-methyl-DCI). DCI differs from myoinositol only by inversion of the configuration of one hydroxyl group on the inositol ring, and DCI is normally present in mammalian blood and urine, though at much lower concentrations than Ins ${ }^{(61)}$. Much of this DCI comes from the diet, and it still not clear whether mammals make DCI from Ins. Ins and DCI have been reported to be interconvertible through the action of an partially characterised epimerase activity that is found in mammalian tissues $^{(58,62)}$, but a study of intact rodents found no evidence for their interconversion in vivo ${ }^{(63)}$.

Some workers promote the virtues of dietary Ins supplements that contain DCI ${ }^{(6)}$, others are non-committal ${ }^{(64,65)}$ and some cite their disadvantages ${ }^{(66)}$. Given the uncertainties about the Biology of DCI - its interconvertibility (or not) with Ins, its role (or not) in insulin signalling and its value (or not) as a supplement - the remainder of this discussion will be confined to exploration of possible ways in which dietary supplements of Ins, a molecule that has many undisputed and well-understood roles in cell function, might help to alleviate the effects of metabolic and hormonal imbalances. DCI and/or 3-O-methyl-DCI undoubtedly have interesting biological effects, including improved diabetic control in Type II diabetics ${ }^{(67)}$, neuroprotection in diabetic mice ${ }^{(68)}$, suppression of inflammation in a mouse asthma model ${ }^{(69)}$, prolongation of fruit-fly lifespan ${ }^{(70)}$ and very rapid activation of $\mathrm{PKB} /$ Akt in cultured endothelial cells ${ }^{(71)}$, but we still have little idea how these are brought about.

\section{Ins and diabetes}

It has been known since the 19th century that excess fluid intake, including that occurring in the various types of diabetes, causes polyuria and accelerates Ins loss into urine ${ }^{(72)}$, and Daughaday et $a l^{(73,74)}$ established long ago that elevated blood glucose competes with inositol for renal reabsorbtion. They concluded

'that the inosituria of diabetes mellitis can be attributed to an increase in the renal clearance of inositol produced by glycosuria'.

This focussed attention on the idea that, secondary to this urinary loss, diabetic people and animals might suffer from an Ins deficiency that would contribute to the pathogenesis of at least some of the disease's long-term consequences, such as neuropathy, nephropathy and retinopathy. Moreover, diabetic mothers, both human and rodent, are at increased risk of producing offspring with neural crest-related malformations, and by 2000 a substantial body of work suggested that a modest Ins deficiency might cause some of these developmental defects ${ }^{(75)}$.

The second route by which the body loses Ins is through its oxidation to glucuronate by proximal tubular myoinositol oxidase in the kidney cortex, with the product metabolised via the glucuronate/xylulose pathway. This route of Ins loss is also over-active in diabetes, hypertension and obesity - and in response to raised plasma insulin concentration, as is typically seen in conditions involving insulin resistance ${ }^{(76-78)}$.

The consequence of these adverse renal events is that any person or animal that is diabetic and/or insulin-resistant, and so is likely to be hyperglycaemic and/or to have elevated circulating insulin, will lose Ins by one or both of these routes and

Table 1. The benefits of ins supplements in human patients and in animal models of human disease

\begin{tabular}{|c|c|c|c|}
\hline Human study subjects & Changes with dietary or other Ins supplementation & $\begin{array}{l}\text { Similar benefits in } \\
\text { animal models? }\end{array}$ & References \\
\hline Men with poor sperm quality & $\begin{array}{l}\text { Improved sperm quality and fertility; increased sperm motility - } \\
\text { in vitro and with vaginal pessaries }\end{array}$ & $\mathrm{N} / \mathrm{A}$ & (158-165) \\
\hline $\begin{array}{l}\text { Women undergoing assisted reproduction to } \\
\text { relieve fertility problems }\end{array}$ & $\begin{array}{l}\text { Improved quality of cultured IVF embryos; more pregnancies with } \\
\text { fewer complications (except reference (168)) }\end{array}$ & Yes & $(66,166-171)$ \\
\hline $\begin{array}{l}\text { Women with PCOS and insulin resistance, } \\
\text { including some non-obese adolescents }\end{array}$ & $\begin{array}{l}\text { Improved hormonal profile; more frequent ovulation and } \\
\text { menstruation; improved fertility; improved insulin sensitivity }\end{array}$ & $\mathrm{N} / \mathrm{A}$ & $(6,64,65,172-179)$ \\
\hline Pregnant women with or at risk of GDM & $\begin{array}{l}\text { Decreased GDM incidence (except reference (188)); improved } \\
\text { insulin sensitivity }\end{array}$ & Yes & $\left({ }^{\star} 180,{ }^{*} 181,182-188\right)$ \\
\hline $\begin{array}{l}\text { Women (and a few men) with high BMI and/or } \\
\text { at risk of MetS and/or T2D }\end{array}$ & Improvement of symptoms in a significant proportion of patients & Yes & (189-195) \\
\hline $\begin{array}{l}\text { Women at risk of adverse pregnancy outcomes } \\
\text { (e.g. from diabetes) }\end{array}$ & $\begin{array}{l}\text { Fewer folate-resistant neural tube defects and large-for-gestational- } \\
\text { age babies }\end{array}$ & Yes & $(4,5,196)$ \\
\hline $\begin{array}{l}\text { Small pre-term infants (some of the Ins } \\
\text { supplements were parenteral) }\end{array}$ & $\begin{array}{l}\text { Decreased incidence of respiratory distress syndrome and } \\
\text { retinopathy of prematurity; fewer neonatal and infant deaths }\end{array}$ & Yes & $\left(3,{ }^{*} 197,198\right)$ \\
\hline $\begin{array}{l}\text { Patients with Hashimoto's autoimmune } \\
\text { hypothyroidism }\end{array}$ & $\begin{array}{l}\text { Fewer antibodies against thyroglobulin and thyroid peroxidase; } \\
\text { lower plasma TSH concentration }\end{array}$ & $\mathrm{N} / \mathrm{A}$ & $(199,200)$ \\
\hline
\end{tabular}

GDM, gestational diabetes mellitus; IVF, in vitro fertilization; N/A, no assessment available; DCl, D-chiro-inositol.

In most of the human studies subjects consumed $1-4 \mathrm{~g}$ of extra Ins per day, which is a readily tolerated amount (see the text), but none of these studies include information that permit judgments about the relative merits of different quantities. Ins was taken in addition to routine folate in most studies of pregnancy (human and rodent). Some of the Ins supplements also contained a small amount of $\mathrm{DCI}$ (typical Ins:DCI ratio 40:1, when present), but the available information allows no conclusions about whether DCI significantly changed the effects of the supplements (see the text). For reasons of space, this table mainly cites recent focussed reviews, recent primary articles and/or meta-analyses apologies to the authors of earlier primary sources who are not cited as a result. Many of the human and animal studies have been summarised in broader reviews ${ }^{(2,4,5,30-32,156,157)}$. Bold reference numbers with asterisks $\left(^{*}\right)$ refer to Cochrane Collaboration systematic reviews. 
will be at increased risk of systemic Ins deficiency. The idea that Ins deficiency may be an important feature of diabetes has therefore become an enduring theme, though without an agreed explanation of how it brings about its effects ${ }^{(2)}$.

\section{Conditions for which dietary Ins supplements are therapeutic}

Published reports on the effects of Ins supplements have fairly consistently reported them to be helpful, based on evidence of variable quality, for a substantial range of human medical conditions and in animal models of these conditions. Table 1 briefly summarises the most convincing of these observations, most of which have been discussed in detail by the reviews cited in the table legend. The condition-specific references within the table include more recent primary sources and also meta-analyses and reviews of earlier studies. A few of the latter are Cochrane Collaboration reviews of the possible clinical benefits of Ins supplements: for example, in preventing or alleviating GDM and in supporting the normal development of premature babies.

Several of the conditions that benefit from Ins supplements including PCOS, GDM, MetS and T2D - involve related metabolic and endocrine derangements and tend to share physiological characteristics such as central obesity, insulin resistance, NAFLD and tissue inflammation. These, in turn, are increasingly being linked at a cellular level with the phenomenon of ER stress in the most affected tissues ${ }^{(55,79-82)}$. Other conditions listed in Table 1 are less obviously related, but ER stress contributes to at least some aspects of the pathologies involved in retinopathy ${ }^{(83)}$, hypothyroidism ${ }^{(84)}$, diabetic embryopathy $^{(85)}$ and defective spermatogenesis ${ }^{(86)}$.

The beneficial studies listed in Table employed supplements of no more than $4 \mathrm{~g}$ Ins per day, without any recorded adverse effects. Moreover, some other trials, mainly in anxiety and depressive disorders, have administered much larger doses of Ins, typically $12-18 \mathrm{~g} / \mathrm{d}$, and have observed neither significant side-effects nor appreciable clinical benefit ${ }^{(87,88)}$

Many of the benefits of inositol supplements that are listed in Table 1 have been observed both in human patients and in more rigorously controlled studies of animal models. Not surprisingly, few of the human studies have been large enough and/or of sufficiently rigorous design to yield unambiguous outcomes that could justify firm clinical recommendations, even when combined in meta-analyses. As a result, the relevant meta-analyses have often concluded with some variant of 'Encouraging, but more studies are needed in larger and more diverse populations'.

We also should not ignore the possibility that studies that remain unpublished, which would be more likely to be negative or inconclusive, might cause some publication bias. For example, the open invitation to submit papers for a 2016/ 2017 themed collection entitled 'Inositol(s) from Bench to Bedside in Endocrinology and Gynecology' in the International Journal of Endocrinology stated that 'inositols play a pivotal role, as drugs (my emphasis), in treating several pathologies such as PCOS, MetS and GDM (https://www.hindawi.com/ journals/ije/si/828614/cfp/). The invitation solicited papers on any aspect of inositols as dietary therapies, but did not suggest that this collection might also have served as an appropriate home for inconclusive or negative findings.

The animal studies have often yielded much clearer evidence of benefits of Ins feeding observed under well-controlled laboratory conditions - for example, in decreasing the prevalence of neural tube defects (NTDs) in the progeny of 'curly tail' mice that are genetically prone to develop folate-resistant NTDs ${ }^{(5,89,90)}$.

\section{Might all benefits of Ins supplements rely on a single mechanism?}

What cellular mechanism(s) underlie the beneficial effects of substantial Ins supplements on the conditions listed in Table 1? Possible explanations are of two types. On the one hand, they might involve multiple effects, with the benefit to each condition having its own individual explanation, as has sometimes been hypothesised (see in next paragraph). Alternatively, it seems more likely that one essential, but still unidentified, set of Ins-dependent cell functions operates less than optimally in all of the Ins-responsive conditions, and that Ins supplements supply extra Ins to support this function.

Several specific effects of the former type have been postulated: these include augmentation of insulin signalling through IPGs (see above), effects on cytoskeletal regulation ${ }^{(91)}$, phosphorylation events downstream of phospholipase C signalling ${ }^{(92)}$ and inositols acting as antioxidants that protect against the reactive oxygen species generated by cell metabolism ${ }^{(93)}$. Several of these would selectively implicate different subsets of the many cell regulation processes that depend on Ins derivatives of low abundance (such as the various PPIn, and maybe IPGs) - but none of these reports has ever, to my knowledge, made any attempt to explain how a modest global Ins deficiency might bring about such selective actions. Indeed, it is hard to imagine how the effects of doubling a person's dietary Ins intake could be targetted at improving metabolic support for any of the various pathways that rely on, or are regulated by, rare Ins-containing cell constituent(s) - and that different faults in such events could contribute selectively to different maladies.

It seems far more likely that there is a single, common, explanation - i.e. that generous Ins supplements ensure that cells always have enough Ins to sustain some central cell processes that rely on an abundant Ins-containing cell constituent. If that is the case, we must answer two questions: (a) which abundant Ins-containing molecule has its supply maintained by the Ins supplements; and (b) what central cell processes are compromised by limiting the supply of this molecule, especially during metabolic and endocrine imbalances?

The remainder of this review will outline an hypothesis that attempts to answer these questions. It will: (a) suggest that metabolically stressed tissues develop a mild Ins deficiency, and that consuming extra Ins supports the increased PtdIns biosynthesis that is needed whenever stressed ER needs to increase its functional capacity and enlarge its membrane area; and (b) discuss how experimentally to test this novel interpretation of how extra dietary Ins improves ER function in stressed cells. 
Ins supplements ensure a sustained supply of Ptdlns - but for what purpose?

PtdIns is the main Ins-containing membrane phospholipid of all eukaryote cells (see below). It is much more abundant than any of a cell's other Ins-containing constituents and is the precursor of most of them. Any substantial decrease in the availability of Ins is therefore likely to diminish a cell's PtdIns supply (see Box 1 and the text below).

However, we know much less about specific functions of PtdIns - assuming there are some? - than we should. This is at least partly because the discovery of the $\operatorname{PtdIns}(4,5) P_{2^{-}}$ dependent phosphoinositidase $C$ signalling pathway in the early 1980s shifted the main focus of the phosphoinositide field away from PtdIns (and the ER) onto PtdIns $(4,5) P_{2}$ (and the $P M)$. And workers in this field have since been kept fully occupied by an unending programme of identifying the various other PPIn and decoding their many functions (at various nonER sites) (as outlined in Fig. 1). As a result, it seems likely that we have been unfairly neglecting the possibility, and maybe likelihood, that PtdIns, a major membrane constituent, has specific roles in membrane function and dynamics that are still to be identified.

One useful outcome of trying to understand the beneficial effects of dietary Ins supplements may be that it makes us pose two important questions ${ }^{(1,94)}$. First, 'Why do cells make so much more PtdIns than they would need if PtdIns only served as a precursor to other Ins-containing cell constituents?' And maybe more fundamentally, Why have phospholipids with an Ins1P beadgroup remained an essential part of the cellular apparatus of Archaea and their Eukaryotic descendants throughout most of the time that there has been life on Earth?

For eukaryotes like us, the most frequently offered answer would still probably be 'PtdIns is the essential precursor from which all of the PPIn are made, so we need plenty of it'. However, this answer won't wash for archaea, because the membranes of most of these diverse organisms contain archaetidylinositol (ArcIns: sn-2,-3-dialkyl-glycero-1-phospho1D-myoinositol) or a close relative, but probably have no phosphorylated $\operatorname{ArcIns} P_{\mathrm{n}}$ derivatives analogous to the PPIn of eukaryotes (except for ArcIns $4 P$ as an intermediate in ArcIns biosynthesis $\left.{ }^{(95)}\right)$. This surely makes it more likely that phospholipids with an unadorned Ins $1 P$ headgroup (ArcIns in archaea, and PtdIns in eukaryotes and a few bacteria) first evolved in archaea to fulfil some fundamental and ubiquitous biological function(s) - which we do not yet understand and that eukaryote cells have both retained this (or these) function(s) and elaborated many more $?^{(1,94)}$

\section{How much Ptdlns, where in the cell is it and how is it made?}

How much PtdIns do cells contain and how is it distributed amongst their membrane systems? There are three key variables for each type of tissue or cell - the total PtdIns concentration, the PtdIns concentration in each organelle and the relative membrane masses of the various organelle systems.

Mammalian cells are typically quoted as having $~ 10 \%$ of their membrane phospholipid as PtdIns ${ }^{(96)}$. PIS has a relatively low affinity for Ins, so the main factor that controls the rate of Ptdins synthesis is the cytosolic free Ins concentration rather than any regulated change in intrinsic PIS activity. PtdIns is $~ 12-27 \%$ of the total phospholipid in Saccharomyces cerevisiae, with the higher figure from yeast grown with abundant exogenous inositol; and when yeast's capacity for PtdIns synthesis is varied genetically it maintains normal growth rates with as little as $4 \%$ PtdIns, but can only grow slowly with $2 \%$ PtdIns $^{(97)}$

Older estimates on mammalian tissues showed total lipidbound Ins concentrations of $\sim 2-3 \mathrm{~mm}$ in brain (ox and guineapig) and liver (rat), with almost all of it in PtdIns ${ }^{(98,99)}$. A recent phosphoinositide analysis of mouse tissues found similar PtdIns concentrations and also determined the relative concentrations of PtdIns, of PtdIns $P$ and $\operatorname{PtdIns} P_{2}$ (their isomers were not resolved) and of Ptdins $P_{3}$. PtdIns was again predominant: it constituted more than $98 \%$ of the total in liver and about $92 \%$ in brain ${ }^{(100)}$

A lipidomic analysis of membranes from cultured RAW264.7 macrophages probably offers the most authoritative information on PtdIns concentrations in organelles: it found slightly more PtdIns per mg membrane protein in the PM than the ER, with considerably less in mitochondria ${ }^{(101)}$. An analysis of cultured mouse embryo fibroblasts also suggested modest PtdIns enrichment in the PM relative to the $\mathrm{ER}^{(102)}$.

Many years ago I measured the distribution of PtdIns amongst well characterised primary cell fractions from rat liver (unpublished results). Ins was acid-liberated from dried lipid extracts, trimethylsilylated and assayed by GLC. About half of the PtdIns was in a microsomal fraction that was $\sim 3$-fold enriched in the ER marker enzyme glucose 6-phosphatase and contained about one-fifth of the sedimentable $60 \%$ of the homogenate protein. There was little PtdIns in a fraction consisting largely of mitochondria ( $\sim$-fold enriched in succinate dehydrogenase).

This information suggests that PtdIns is distributed fairly evenly amongst a cell's membranes, except for a considerably lower concentration in mitochondrial inner membranes ${ }^{(96)}$. In many cells, therefore, the bulk of the PtdIns will be in the pervasive tubuloreticular membrane network that makes up the ER, the cell's most extensive membrane system ${ }^{(103,104)}$ (as illustrated in Fig. 1). This is also where phosphatidate (PtdOH) either synthesised de novo or made by diacylglycerol kinase from phosphoinositidase C-liberated $s n$-1,2-diacylglycerol - is converted to PtdIns by a two-step pathway. First, cytidine diphosphate diacylglycerol (CDP-DG) synthase(s) (CDS1 and/ or CDS2 in mammals) converts PtdOH to CDP-DG; and then a single PIS (PIS/CDIPT) transfers a phosphatidyl grouping from CDP-DG to the D-1-hydroxyl group of Ins. CDS1, CDS2 and PIS are all integral ER membrane proteins that have their active sites oriented towards the cytoplasm ${ }^{(105-107)}$. There is growing evidence that there are important spatial and temporal controls over the non-homogeneous distribution of PtdIns and its biosynthesis within the $\mathrm{ER}^{(108-112)}$, but most of this discussion will ignore these important details and consider the ER as a single extensive membrane entity that makes PtdIns and other membrane lipids for use by all of the cell's membranes.

The majority of the PtdIns and PPIn molecules in many or most mammalian cells have, for ill-understood reasons, a remarkably 
homogenous fatty acyl composition, with a C18:0 (stearoyl) group on the $s n-1$ position of the glycerol backbone and a C20:4 (arachidonyl) group on the $s n-2$ position ${ }^{(113)}$. Much of the PtdIns that PIS makes is first synthesised with other fatty acid complements and is then remodelled by a phospholipase/acyltransferase cycle in which an arachidonyl-selective 2-acyltransferase (lysoPtdIns acyltransferase-1 (LPIAT1); also known as MBOAT7) is a major participant. LPIAT1 is essential both for mice to develop normally and for their PtdIns to achieve its distinctive fatty acid pairing ${ }^{(114)}$. The tissues of the short-lived mice that lack LPIAT1 contain much less PtdIns than normal animals and their PtdIns is arachidonyl-depleted. In humans, inactivating mutations in LPIAT1/MBOAT7 give rise to a severe neurodevelopmental syndrome characterised by intellectual disability, autism and epilepsy ${ }^{(115)}$, and humans carrying LPIAT1 allele rs641738, which has reduced expression, have a predisposition to liver steatosis, inflammation and necrosis ${ }^{(116-119)}$.

It therefore seems that if mammals are to survive, be healthy and have a normal PtdIns complement, they must be able correctly to make and to remodel a cytoplasm-facing ER pool of PtdIns that has several functions: (a) it exports PtdIns to the cytoplasmic leaflets of the cell's other membranes, where some cycles rapidly in and out of small metabolic pools of the cell's seven organelle-specific PPIn (see Box 1 and Fig. 1); (b) some of the PtdIns flips to face the ER lumen, where its fatty acid pattern is remodelled and it is incorporated into GPI anchors that will moor proteins to the exterior of the $\mathrm{PM}^{(16,120)}$; and (c) it contributes about one-tenth of the phospholipid that makes up the lipid bilayer in the ER membrane, so we must assume that more PtdIns must be made whenever the ER needs to be enlarged.

\section{The UPR and ER membrane expansion: two faces of cell responses to ER stress}

The remainder of this discussion will focus on the importance of maintaining an adequate PtdIns supply in order to support ER membrane homeostasis. The events by which cells respond to ER stress have been studied in exquisite detail in the yeast $S$. cerevisiae, much less in cultured mammalian cells and - despite the mounting evidence that perturbation of ER homeostasis is an important feature of many metabolic and endocrine disorders - only to a limited extent in intact mammals ${ }^{(45-47)}$. Moreover, it is increasingly being recognised that the suite of cellular adaptive events that generally sails under the 'ER stress' flag is simply an extreme version of a set of processes by which cells constantly modulate their everyday functions as they adapt to fluctuating nutrient supplies, diurnal bodily rhythms, and etc. ${ }^{(44,121-124)}$.

The original yeast experiments revealed the key features of a set of archetypal ER stress responses in which activation of a single transmembrane ER protein (IRE1) coordinates a suite of events in which:

(1) the complex UPR apparatus identifies and disposes of aberrant newly synthesised proteins, regulates the ER's ongoing protein load, and orchestrates a suite of genes whose products enhance the ER's luminal capacity for post-translational processing, folding and quality control of proteins;
(2) the ER expands its membrane area, a process that demands accelerated synthesis of phospholipids to enlarge the membrane bilayer, and this expansion both increases the internal volume within the ER for protein processing and allows the membranes of the ER to accommodate more intrinsic proteins without the lipid bilayer becoming over-crowded; or

(3) the ER does both of the above in a coordinated manner (reviewed in references 23,41,42).

In mammalian cells, the various elements of the ER homeostatic responses are regulated in more complex, and sometimes tissue-specific, ways by the interplay of five transmembrane regulators (IRE1 $\alpha$, IRE1 $\beta$, PERK, $\operatorname{ATF} 6 \alpha$ and $\operatorname{ATF} 6 \beta$ ) and the proteins with which they functionally interact ${ }^{(41,42,44,125)}$.

This discussion will focus on the membrane expansion arm of this dichotomy, since this is the process that particularly requires a coordinated increase in the synthesis of all of the phospholipids, including PtdIns, that make up the lipid bilayer of ER (and other) membranes.

The UPR, which is the ER's response to protein misfolding within its lumen, is mainly initiated through interactions between any aberrant proteins that accumulate within the ER lumen and the luminal domains of these transmembrane regulators, especially IRE $1 \alpha^{(41,42)}$. It was therefore a surprise when it was discovered that truncated transmembrane versions of IRE1 $\alpha$ and ATF $6 \alpha$ that lack these luminal sensing domains can retain their ability to initiate dramatic increases in ER membrane biosynthesis. Occasionally this membrane expansion has been assessed directly (e.g. by fluorescence microscopy of cells expressing tagged variants of ER-resident proteins or by examination of thin-section electron micrographs ${ }^{(126-128)}$ ) but more often it is detected less directly as an increase in the expression and/or activity of phospholipid-synthesising enzymes - usually CTP:phosphocholine cytidylyltransferase, the rate-limiting enzyme in phosphatidylcholine (PtdCho) synthesis by the Kennedy pathway ${ }^{(23,125,129-131)}$.

Effective inducers of such membrane expansion include exposure to exogenous saturated fatty acids (e.g. palmitate, C16:0), inhibition of the desaturation of endogenous stearate (C18:0) and the over-expression of intrinsic ER proteins - or of shortened constructs thereof that include little more than the relevant protein's membrane-spanning domain. It therefore seems that the bilayer-spanning parts of the ER stress sensors (or of their membrane-spanning intrinsic ER partner proteins $\left.{ }^{(132)}\right)$ somehow sense an excessive degree of physical order within the membrane bilayer - caused, for example, by protein overcrowding or by a relatively saturated lipid environment - and compensate by initiating synthesis of the extra phospholipid that is needed to expand the area of ER lipid bilayer in which the proteins reside ${ }^{(133-139)}$. Remarkably, a recent study of variant IRE $1 \alpha$ constructs showed that major changes can be made to the amino-acid sequence of this protein's transmembrane domain without substantially changing its ability to initiate this response ${ }^{(140)}$.

Most efforts to explain control of the extra phospholipid synthesis that is needed to support ER membrane expansion have focussed, both in yeast and in mammalian cells, on 
defining how these ER stress sensors stimulate extra synthesis of the PtdCho that makes up about half of the phospholipid of the ER's lipid bilayer ${ }^{(96,125,131,141)}$. Much less in known about the relative importance of phosphatidylethanolamine (PtdEtn), the second most abundant phospholipid of the ER, and of phosphatidylserine (PtdSer) and PtdIns, the other invariant and essential ER membrane phospholipids, and of how their biosyntheses are regulated ${ }^{(142)}$. But one defined consequence of genetically limiting liver cells' ability to make either PtdEtn or PtdSer is to provoke hepatic ER stress, especially when the resulting PtdCho:PtdEtn ratio in the liver, which is normally around $1 \cdot 6$, substantially deviates to higher or lower values ${ }^{(143)}$. Ongoing synthesis of these glycerophospholipids by the ER must, of course, also maintain an adequate supply of these membrane lipids to all of the cells' other membranes, and the complex set of distribution processes by which this is achieved is finally beginning to be understood ${ }^{(141,143-145)}$.

\section{How might we explore the role of Ptdlns in ER function in mammalian cells and in animals?}

It was yeast's requirement for Ins as the essential PtdIns precursor that gave the name IRE1 to the prototypic ER stress sensor of yeast. The effects of limiting the supply of exogenous Ins to growing yeast are many, including: induction of the expression of Ino1, and thus of endogenous Ins production; a substantial decrease in the steady-state PtdIns concentration; a compensatory slowing of the synthesis of other membrane phospholipids, notably PtdCho, that are needed for membrane maintenance and expansion; and delaying the synthesis and trafficking of the GPI anchors of proteins destined for the PM. Overall, changing the availability of exogenous Ins influences the expression of at least 700 yeast genes ${ }^{(23)}$

The arguments presented above suggest that the most likely interpretation of the beneficial effects of dietary Ins supplements on various metabolic and endocrine imbalances in mammals is that they correct an Ins deficiency that prevents stressed ER from making enough PtdIns. So how can that idea be experimentally tested - ideally both in isolated and/or cultured cells and in intact animals? During recent decades we have been inundated by a flood of discoveries of 'new' and essential cell functions that rely on molecules made from PtdIns, especially the various PPIn, and this means that deciphering any specific functions of PtdIns will not be easy.

Analysis of the many functions of the PPIn has been facilitated by the development of an ingenious armoury of specific cell-biological tools that allow us to follow their individual distributions and movements in intact cells and to manipulate their concentrations enzymatically at localised intracellular sites $^{(7-10)}$. However, there are not yet equivalent tools of high specificity with which to explore the functions of PtdIns - or, indeed, of any of the other abundant glycerophospholipids (PtdCho, PtdEtn and PtdSer) that, in various mixtures, dominate the core lipid bilayers of eukaryote cell membranes.

For example, we largely lack data, equivalent to those from yeast, on the effects of changing PtdIns-synthetic capacity or the availability of exogenous Ins on ER homeostasis in mammalian cells. Early studies established how much exogenous Ins various cultured cells need to support maximal growth, usually $1-3 \mu \mathrm{m}$, but nothing more ${ }^{(21)}$. And when, more recently, cultured cells have been radiolabelled for metabolic studies, this has generally been done at the lowest possible - and least costly - concentration that would kept them healthy (or at least 'growing at an unrestrained rate under the conditions chosen for the experiment'). For example, $\sim 5 \mu \mathrm{m}$ Ins was the lowest concentration at which the HL60 promyeloid cells that we studied grew exponentially and appeared to differentiate normally towards neutrophils or monocytes ${ }^{(146)}$.

Unfortunately, such measurements tell us nothing about whether this would have remained an adequate Ins supply if these cultured cells had been subjected to the sorts of sustained demand for phospholipid biosynthesis that are seen during extensive ER membrane proliferation events: for example, (a) during the differentiation of immature B-lymphocytes, which have little ER, into ER-packed and Ig-secreting plasma cells ${ }^{(147,148)}$; or (b) in response to provocations such as the various artificial membrane stresses mentioned above. Studies of the Ins requirements of - and the effects of Ins deprivation on - cells undergoing such adaptations should be very informative. Might Ins restriction limit their ER expansion and provoke overt ER stress, and maybe cause them to develop neutral lipid inclusions? Might the cells even bud off inflammationprovoking membrane vesicles in a manner similar to stressed hepatocytes $^{(149)}$ - and/or undergo stress-induced apoptosis?

Another ER stressor is high-fat feeding, which has long been known to potentiate the development of an Ins-responsive fatty liver in Ins-deprived animals ${ }^{(22,26)}$. When diabetes-prone mice were fed an extreme version of a high-fat diet for 1-4 months they developed a model of Type 2 diabetes that included tissue Ins depletion, inosituria and insulin resistance, some of which were partly reversed by feeding of large Ins supplements ${ }^{(150)}$.

Remembering that the nutrient drain of lactation was another potentiator of classical Ins deficiency-triggered liver steatosis (see earlier) ${ }^{(26)}$, one might also ask how limiting Ins supply would influence the mammary epithelium's pre-partum differentiation in preparation for the start of lactation, a process in which the IRE1 effector XBP1 is now known to play an essential role ${ }^{(151,152)}$. It is known that women affected by GDM, a condition for which dietary Ins seems to be beneficial (see Table 1), tend to breastfeed less successfully than non-GDM mothers ${ }^{(153)}$. This is potentially detrimental both to the infant's nutrition and to the subsequent health of the mother ${ }^{(154)}$. Might continuing to take Ins supplements during lactation improve this situation by enhancing mammary function and Insenriching the mother's milk - and thus help to sustain breastfeeding and improve the offspring's nutrition? And might it also improve the mother's chance of avoiding continued diabetes after her pregnancy?

In a broader context, one of the first things that might be done in a revival of 'old-fashioned' studies of rats, mice or gerbils would be to test the simple prediction that making these animals Ins-deficient would provoke many of their tissues to display diagnostic biochemical features of ER stress, and that these might be detectable well before the development of more overt features such as a fatty liver. 


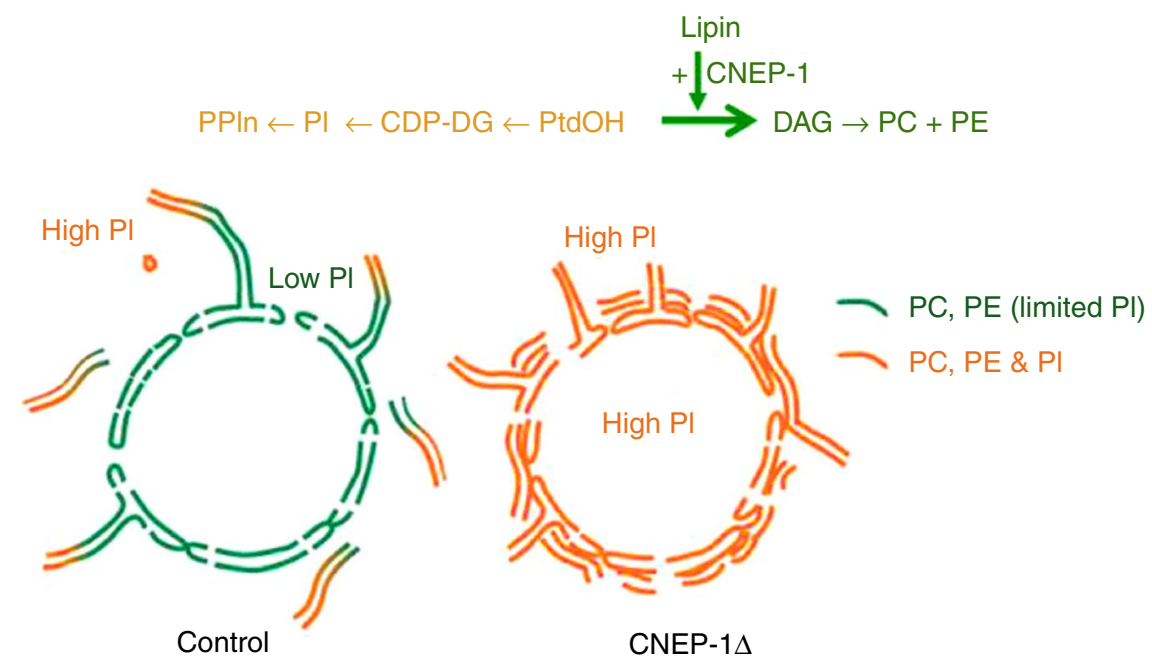

Fig. 2. Redirection of phospholipid synthesis by activation of phosphatidate (PtdOH) phosphatase causes the nuclear envelope to be relatively phosphatidylinositol (Ptdlns)-depleted compared with the extra-nuclear endoplasmic reticulum (ER). The nuclear envelope-resident protein C-terminal domain Nuclear Envelope Phosphatase-1 (CNEP-1) activates lipin, a PtdOH phosphohydrolase, on membrane structures involved in nuclear envelope breakdown during cell division, so favouring the conversion of PtdOH to sn-1,2-diacylglycerol (DAG) over formation of cytidine diphosphate diacylglycerol (CDP-DG) (see upper pathway). As a result, the balance of phospholipid synthesis in these membranes is skewed away from Ptdlns (PI) and towards PtdCho (PC) and PtdEtn (PE). The nuclear envelope therefore has a lower Ptdlns content than the remainder of the ER continuum, and this somehow ensures that obstructive ectopic ER cisternae do not accumulate around the nucleus (lower schematic diagram). This figure is adapted, with permission, from Figure 1 of reference (112).

Finally, what do we know about the spatial organisation of the metabolism of PtdIns within the complex and ever-changing topology of the ER; what might its heterogenous distribution mean; and how might it be perturbed experimentally? First, it has recently been becoming clear that PIS, and thus PtdIns synthesis, tends to be concentrated in some peripheral elements of the ER, particularly where tubulovesicular elements make close contacts with other organelles ${ }^{(108-111)}$ - although it will usually still be assumed that the new PtdIns equilibrates rapidly throughout the cytoplasmic surface of interconnecting ER membranes.

A hint that this may not always be true comes from an intriguing study of the role of the nuclear envelope protein CNEP-1 (C-terminal domain Nuclear Envelope Phosphatase-1), an activator of the phosphatidate (PtdOH) phosphatase known as lipin, in regulating nuclear membrane dynamics in Caenorbabditis elegans embryos. As illustrated in Fig. 2, the activity of this widely conserved regulator of substrate partitioning during glycerophospholipid synthesis somehow ensures that ectopic sheets of ER do not surround the nucleus and interfere with the normal dynamics of nuclear envelope disassembly during mitosis. The activated PtdOH phosphatase directs biosynthetic flux away from CDP-DG and PtdIns, and so dictates that the nuclear envelope lipid bilayer contains less PtdIns than the 'bulk' ER. Confirmation that this relative nuclear depletion of PtdIns contributes to the sub-compartmentation of ER membrane distribution comes from the fact that global inhibition of PtdIns production can counteract the accumulation of these interfering perinuclear ER structures even when CNEP-1 is inhibited ${ }^{(112,155)}$. How this happens remains a mystery.

\section{Conclusion}

The observations discussed here suggest, rather surprisingly, that eating some daily inositol might make a simple dietary contribution to alleviating several common disorders. Drug companies have spent many years and many fortunes trying to find novel and costly treatments for these conditions, and the resulting drugs sometimes have unpleasant side-effects - whereas eating some extra Ins, a normal and inexpensive dietary constituent, seems benign. However, it remains worrying that well-validated explanations for its beneficial effects still elude us. Maybe the ideas put forward here might help to get us on the right track?

\section{Acknowledgements}

Several colleagues have offered valuable comments on these ideas as they have been developing. My particular thanks to Tamas Balla, Clifford Bailey, Gerry Hammond, Yusuf Hannun, Phill Hawkins, Esther Oppenheim and Len Stephens.

This research received no specific grant from any funding agency or from any commercial or not-for-profit sectors.

The author declares that there are no conflicts of interest.

\section{References}

1. Michell RH (2008) Inositol derivatives: evolution and functions. Nature Rev Mol Cell Biol 9, 151-161.

2. Croze ML \& Soulage CO (2013) Potential role and therapeutic interests of myo-inositol in metabolic diseases. Biochimie 95, 1811-1827.

3. Hallman M (2015) Inositol during perinatal transition. NeoReviews 16, e84-e93.

4. Noventa M, Vitagliano A, Quaranta M, et al. (2016) Preventive and therapeutic role of dietary inositol supplementation in periconceptional period and during pregnancy: a summary of evidences and future applications. Reprod Sci 23, 278-288.

5. Greene NDE, Leung KY \& Copp AJ (2017) Inositol, neural tube closure and the prevention of neural tube defects. Birth Defects Res 109, 68-80. 
6. Monastra G, Unfer V, Harrath AH, et al. (2017) Combining treatment with myo-inositol and D-chiro-inositol (40:1) is effective in restoring ovary function and metabolic balance in PCOS patients. Gynecol Endocrinol 33, 1-9.

7. Di Paolo G \& De Camilli P (2006) Phosphoinositides in cell regulation and membrane dynamics. Nature 443, 651-657.

8. Botelho RJ (2009) Changing phosphoinositides 'on the fly' how trafficking vesicles avoid an identity crisis. Bioessays $\mathbf{3 1}$, $1127-1136$.

9. Balla T (2013) Phosphoinositides: tiny lipids with giant impact on cell regulation. Physiol Rev 93, 1019-1137.

10. Hammond GR \& Balla T (2015) Polyphosphoinositide binding domains: key to inositol lipid biology. Biochim Biophys Acta 1851, 746-758.

11. Shears SB (1998) The versatility of inositol phosphates as cellular signals. Biochim Biophys Acta 1436, 49-67.

12. Shears SB (2009) Diphosphoinositol polyphosphates: metabolic messengers? Mol Pharmacol 76, 236-252.

13. Monserrate JP \& York JD (2010) Inositol phosphate synthesis and the nuclear processes they affect. Curr Opin Cell Biol 22, 365-373.

14. Wilson MS, Livermore TM \& Saiardi A (2013) Inositol pyrophosphates: between signalling and metabolism. Biochem $J$ 452, 369-379.

15. Low MG (1987) Biochemistry of the glycosylphosphatidylinositol membrane protein anchors. Biochem $J$ 244, 1-13.

16. Zurzolo C \& Simons K (2016) Glycosylphosphatidylinositolanchored proteins: membrane organization and transport. Biochim Biophys Acta 1858, 632-639.

17. Majumder AL, Chatterjee A, Ghosh Dastidar K, et al. (2003) Diversification and evolution of L-myo-inositol 1-phosphate synthase. FEBS Lett 553, 3-10.

18. Schneider $S$ (2015) Inositol transport proteins. FEBS Lett 589 , 1049-1058.

19. Reynolds TB (2009) Strategies for acquiring the phospholipid metabolite inositol in pathogenic bacteria, fungi and protozoa: making it and taking it. Microbiology 155, 1386-1396.

20. González-Salgado A, Steinmann M, Major LL, et al. (2015) Trypanosoma brucei bloodstream forms depend upon uptake of myo-inositol for Golgi complex phosphatidylinositol synthesis and normal cell growth. Eukaryot Cell 14, 616-624

21. Eagle H, Oyama VI, Levy M, et al. (1957) Myo-Inositol as an essential growth factor for normal and malignant human cells in tissue culture. J Biol Chem 226, 191-205.

22. Holub BJ (1986) Metabolism and function of $m y o$-inositol and inositol phospholipids. Annu Rev Nutr 6, 563-597.

23. Henry SA, Gaspar ML \& Jesch SA (2014) The response to inositol: regulation of glycerolipid metabolism and stress response signaling in yeast. Chem Phys Lipids 180, 23-43.

24. Ohnishi T, Murata T, Watanabe A, et al. (2014) Defective craniofacial development and brain function in a mouse model for depletion of intracellular inositol synthesis. $J$ Biol Chem 289, 10785-10796.

25. Clements RS \& Darnell B (1980) Myo-inositol content of common foods: development of a high-myo-inositol diet. Am J Clin Nutr 33, 1954-1967.

26. Wells WW (1989) Inositol deficiency states as a guide to inositol function. In Inositol Lipids in Cell Signalling, pp. 209-238 [RH Michell, AH Drummond and CP Downes, editors]. London: Academic Press.

27. Schlemmer U, Frølich W, Prieto RM, et al. (2009) Phytate in foods and significance for humans: food sources, intake, processing, bioavailability, protective role and analysis. $\mathrm{Mol}$ Nutr Food Res 53, Suppl. 2, S330-S375.

28. Dinicola S, Minini M, Unfer V, et al. (2017) Nutritional and acquired deficiencies in inositol bioavailability. Correlations with metabolic disorders. Int J Mol Sci 18, E2187.

29. Wilson MS, Bulley SJ, Pisani F, et al. (2015) A novel method for the purification of inositol phosphates from biological samples reveals that no phytate is present in human plasma or urine. Open Biol 5, 150014.

30. Beemster P, Groenen P \& Steegers-Theunissen R (2002) Involvement of inositol in reproduction. Nutr Rev $\mathbf{6 0}, 80-87$.

31. Papaleo E, Unfer V, Baillargeon JP, et al. (2009) Contribution of myo-inositol to reproduction. Eur J Obstet Gynecol Reprod Biol 147, 120-123.

32. Muscogiuri G, Palomba S, Laganà AS, et al. (2016) Inositols in the treatment of insulin-mediated diseases. Int J Endocrinol 2016, 3058393.

33. Chu SW \& Geyer RP (1982) Myo -inositol action on gerbil intestine: association of phosphatidylinositol metabolism with lipid clearance. Biochim Biophys Acta 710, 63-70.

34. Chu SW, Geyer RP \& Walker WA (1987) Myo-inositol action on gerbil intestine: alterations in alkaline phosphatase activity upon phosphatidylinositol depletion and repletion in vivo. Biochim Biophys Acta 929, 220-225.

35. Henkel A \& Green RM (2013) The unfolded protein response in fatty liver disease. Semin Liver Dis 33, 321-329.

36. Lonardo A, Ballestri S, Marchesini G, et al. (2015) Nonalcoholic fatty liver disease: a precursor of the metabolic syndrome. Dig Liver Dis 47, 181-190.

37. Wahlang B, Beier JI, Clair HB, et al. (2013) Toxicantassociated steatohepatitis. Toxicol Pathol 41, 343-360.

38. Bruce KD \& Byrne CD (2009) The metabolic syndrome: common origins of a multifactorial disorder. Postgrad Med J 85, 614-621.

39. Targher G, Rossini M \& Lonardo A (2016) Evidence that nonalcoholic fatty liver disease and polycystic ovary syndrome are associated by necessity rather than chance: a novel hepato-ovarian axis? Endocrine 51, 211-221.

40. Ajmera VH, Gunderson EP, Van Wagner LB, et al. (2016) Gestational diabetes mellitus is strongly associated with non-alcoholic fatty liver disease. Am J Gastroenterol 111, 658-664.

41. Ron D \& Walter P (2007) Signal integration in the endoplasmic reticulum unfolded protein response. Nature Rev Mol Cell Biol 8, 519-529.

42. Mori K (2009) Signalling pathways in the unfolded protein response: development from yeast to mammals. $J$ Biochem 146, $743-750$.

43. Lee AH \& Glimcher LH (2009) Intersection of the unfolded protein response and hepatic lipid metabolism. Cell Mol Life Sci 66, 2835-2850.

44. Walter P \& Ron D (2011) The unfolded protein response: from stress pathway to homeostatic regulation. Science 334, 1081-1086.

45. Pagliassotti MJ (2012) Endoplasmic reticulum stress in nonalcoholic fatty liver disease. Annu Rev Nutr 32, 17-33.

46. Malhi H \& Kaufman RJ (2011) Endoplasmic reticulum stress in liver disease. J Hepatol 54, 795-809.

47. Ariyasu D, Yoshida H \& Hasegawa Y (2017) Endoplasmic reticulum (ER) stress and endocrine disorders. Int J Mol Sci 18, pii: E382.

48. Nikawa J \& Yamashita S (1992) IRE1 encodes a putative protein kinase containing a membrane-spanning domain and is required for inositol phototrophy in Saccharomyces cerevisiae. Mol Microbiol 6, 1441-1446. 
49. Alb JG Jr, Cortese JD, Phillips SE, et al. (2003) Mice lacking phosphatidylinositol transfer protein-alpha exhibit spinocerebellar degeneration, intestinal and hepatic steatosis, and hypoglycemia. J Biol Chem 278, 33501-33518.

50. Alb JG Jr, Phillips SE, Wilfley LR, et al. (2007) The pathologies associated with functional titration of phosphatidylinositol transfer protein alpha activity in mice. J Lipid Res $\mathbf{4 8}$, 1857-1872.

51. Nile AH, Bankaitis VA \& Grabon A (2010) Mammalian diseases of phosphatidylinositol transfer proteins and their homologs. Clin Lipidol 5, 867-897.

52. Thakur PC, Stuckenholz C, Rivera MR, et al. (2011) Lack of de novo phosphatidylinositol synthesis leads to endoplasmic reticulum stress and hepatic steatosis in cdipt-deficient zebrafish. Hepatology 54, 452-462.

53. Thakur PC, Davison JM, Stuckenholz C, et al. (2014) Dysregulated phosphatidylinositol signaling promotes endoplasmic-reticulum-stress-mediated intestinal mucosal injury and inflammation in zebrafish. Dis Model Mech 7, 93-106.

54. Liu Y, Wang W, Shui G, et al. (2014) CDP-diacylglycerol synthetase coordinates cell growth and fat storage through phosphatidylinositol metabolism and the insulin pathway. PLoS Genet 10, e1004172.

55. Thomas SE, Dalton LE, Daly ML, et al. (2010) Diabetes as a disease of endoplasmic reticulum stress. Diabetes Metab Res Rev 26, 611-621.

56. Cantley LC (2002) The phosphoinositide 3-kinase pathway. Science 296, 1655-1657.

57. Larner J, Galasko G, Cheng K, et al. (1979) Generation by insulin of a chemical mediator that controls protein phosphorylation and dephosphorylation. Science 206, 1408-1410.

58. Larner J, Brautigan DL \& Thorner MO (2010) D-chiro-inositol glycans in insulin signaling and insulin resistance. $\mathrm{Mol} \mathrm{Med}$ 16, 543-552.

59. Hecht ML, Tsai YH, Liu X, et al. (2010) Synthetic inositol phosphoglycans related to GPI lack insulin-mimetic activity. ACS Chem Biol 5, 1075-1086.

60. Suzuki S, Suzuki C, Hinokio Y, et al. (2014) Insulinmimicking bioactivities of acylated inositol glycans in several mouse models of diabetes with or without obesity. PLOS ONE 9, e100466.

61. Hong JH, Jang HW, Kang YE, et al. (2012) Urinary chiro- and myo-inositol levels as a biological marker for type 2 diabetes mellitus. Disease Markers 33, 193-199.

62. Unfer V, Carlomagno G, Papaleo E, et al. (2014) Hyperinsulinemia alters myoinositol to D-chiroinositol ratio in the follicular fluid of patients with PCOS. Reprod Sci 21, $854-858$

63. Lin X, Ma L, Gopalan C, et al. (2009) D-chiro-Inositol is absorbed but not synthesised in rodents. Br J Nutr $\mathbf{1 0 2}$, 1426-1434.

64. Galletta M, Grasso S, Vaiarelli A, et al. (2011) Bye-bye chiroinositol - myo-inositol: true progress in the treatment of polycystic ovary syndrome and ovulation induction. Eur Rev Med Pharmacol Sci 15, 1212-1214.

65. Facchinetti F, Bizzarri M, Benvenga S, et al. (2015) Results from the international consensus conference on myo-inositol and D-chiro-inositol in obstetrics and gynecology: the link between metabolic syndrome and PCOS. Eur $J$ Obstet Gynecol Reprod Biol 195, 72-76.

66. Garg D \& Tal R (2016) Inositol treatment and ART outcomes in women with PCOS. Int J Endocrinol 2016, 1979654.

67. Kim JI, Kim JC, Kang MJ, et al. (2005) Effects of pinitol isolated from soybeans on glycaemic control and cardiovascular risk factors in Korean patients with Type II diabetes mellitus: a randomized controlled study. Eur J Clin Nutr 59, 456-458.

68. Farias VX, Macêdo FH, Oquendo MB, et al. (2011) Chronic treatment with D-chiro-inositol prevents autonomic and somatic neuropathy in STZ-induced diabetic mice. Diabetes Obes Metab 13, 243-250.

69. Lee JS, Lee CM, Jeong YI, et al. (2007) D-pinitol regulates Th1/Th2 balance via suppressing Th2 immune response in ovalbumin-induced asthma. FEBS Lett 581, 57-64.

70. Hada B, Yoo MR, Seong KM, et al. (2013) D-chiro-inositol and pinitol extend the life span of Drosophila melanogaster. J Gerontol A Biol Sci Med Sci 68, 226-234.

71. D'Oria R, Laviola L, Giorgino F, et al. (2017) PKB/Akt and MAPK/ERK phosphorylation is highly induced by inositols: novel potential insights into endothelial dysfunction in preeclampsia. Pregnancy Hypertens 10, 107-112.

72. Needham J (1924) Studies on inositol. II. The synthesis of inositol in the animal body. Biochem J 18, 891-904.

73. Daughaday WH \& Larner J (1954) The renal excretion of inositol in normal and diabetic human beings. $J$ Clin Invest 33, 326-332.

74. Daughaday WH, Larner J \& Houghton E (1954) The renal excretion of inositol by normal and diabetic rats. J Clin Invest 33, 1075-1080.

75. Eriksson UJ, Borg LA, Cederberg J, et al. (2000) Pathogenesis of diabetes-induced congenital malformations. Uppsala J Med Sci 105, 53-84.

76. Chang HH, Chao HN, Walker CS, et al. (2015) Renal depletion of myo-inositol is associated with its increased degradation in animal models of metabolic disease. $\mathrm{Am} \mathrm{J}$ Physiol Renal Physiol 309, F755-F763.

77. Sun L, Dutta RK, Xie P, et al. (2016) Myo-inositol oxygenase over-expression accentuates generation of reactive oxygen species and exacerbates cellular injury following high glucose ambience: a new mechanism relevant to the pathogenesis of diabetic nephropathy. J Biol Chem 291, 5688-5707.

78. Tominaga T, Dutta RK, Joladarashi D, et al. (2016) Transcriptional and translational modulation of myo-inositol oxygenase (MIOX) by fatty acids: implications in renal tubular injury induced in obesity and diabetes. $\mathrm{J} \mathrm{Biol} \mathrm{Chem}$ 291, 1348-1367.

79. Liong S \& Lappas M (2015) Endoplasmic reticulum stress is increased in adipose tissue of women with gestational diabetes. PLOS ONE 10, e0122633.

80. Keane KN, Cruzat VF, Carlessi R, et al. (2015) Molecular events linking oxidative stress and inflammation to insulin resistance and $\beta$-cell dysfunction. Oxid Med Cell Longev 2015, 181643

81. Yung HW, Alnæs-Katjavivi P, Jones CJ, et al. (2016) Placental endoplasmic reticulum stress in gestational diabetes: the potential for therapeutic intervention with chemical chaperones and antioxidants. Diabetologia 59, 2240-2250.

82. Bañuls C, Rovira-Llopis S, Martinez de Marañon A, et al. (2017) Metabolic syndrome enhances endoplasmic reticulum, oxidative stress and leukocyte-endothelium interactions in PCOS. Metabolism 71, 153-162.

83. Zhang SX, Ma JH, Bhatta M, et al. (2015) The unfolded protein response in retinal vascular diseases: implications and therapeutic potential beyond protein folding. Prog Retin Eye Res 45, 111-131.

84. Zhou L, Ding S, Li Y, et al. (2016) Endoplasmic reticulum stress may play a pivotal role in lipid metabolic disorders in a novel mouse model of subclinical hypothyroidism. Sci Rep 6, 31381. 
85. Wang F, Weng H, Quon MJ, et al. (2015) Dominant negative FADD dissipates the proapoptotic signalosome of the unfolded protein response in diabetic embryopathy. $A m \mathrm{~J}$ Physiol Endocrinol Metab 309, E861-E873.

86. Guzel E, Arlier S, Guzeloglu-Kayisli O, et al. (2017) Endoplasmic reticulum stress and homeostasis in reproductive physiology and pathology. Int J Mol Sci 18, pii: E792.

87. Carlomagno G \& Unfer V (2011) Inositol safety: clinical evidences. Eur Rev Med Pharmacol Sci 15, 931-936.

88. Mukai T, Kishi T, Matsuda Y, et al. (2014) A meta-analysis of inositol for depression and anxiety disorders. Hum Psychopharmacol 29, 55-63.

89. Cockroft DL, Brook FA \& Copp AJ (1992) Inositol deficiency increases the susceptibility to neural tube defects of genetically predisposed (curly tail) mouse embryos in vitro. Teratology 45, 223-232.

90. Greene ND \& Copp AJ (1997) Inositol prevents folateresistant neural tube defects in the mouse. Nature Med $\mathbf{3}$ 60-66.

91. Bizzarri M, Cucina A, Dinicola S, et al. (2016) Does myoinositol effect on PCOS follicles involve cytoskeleton regulation? Med Hypotheses 91, 1-5.

92. Cogram P, Hynes A, Dunlevy LPE, et al. (2004) Specific isoforms of protein kinase $\mathrm{C}$ are essential for prevention of folate-resistant neural tube defects by inositol. Hum $\mathrm{Mol}$ Genet 13, 7-14.

93. Artini PG, Casarosa E, Carletti E, et al. (2017) In vitro effect of myo-inositol on sperm motility in normal and oligoasthenospermia patients undergoing in vitro fertilization. Gynecol Endocrinol 33, 109-112.

94. Michell RH (2013) Inositol lipids: from an archaeal origin to phosphatidylinositol 3,5-bisphosphate faults in human disease. FEBS J 280, 6281-6294.

95. Morii H, Kiyonari S, Ishino Y, et al. (2009) A novel biosynthetic pathway of archaetidyl-myo-inositol via archaetidylmyo-inositol phosphate from CDP-archaeol and D-glucose 6-phosphate in methanoarchaeon Methanothermobacter thermautotrophicus cells. J Biol Chem 284, 30766-30774.

96. Vance JE (2015) Phospholipid synthesis and transport in mammalian cells. Traffic 16, 1-18.

97. Jani NM \& Lopes JM (2009) Regulated transcription of the Saccharomyces cerevisiae phosphatidylinositol biosynthetic gene, PIS1, yields pleiotropic effects on phospholipid synthesis. FEMS Yeast Res 9, 552-564

98. Dawson RM \& Eichberg J (1965) Diphosphoinositide and triphosphoinositide in animal tissues. Extraction, estimation and changes post mortem. Biochem J 96, 634-643.

99. Michell RH, Hawthorne JN, Coleman R, et al. (1970) Extraction of polyphosphoinositides with neutral and acidified solvents. A comparison of guinea-pig brain and liver, and measurements of rat liver inositol compounds which are resistant to extraction. Biochim Biophys Acta 210, 86-91.

100. Anderson KE, Kielkowska A, Durrant TN, et al. (2013) Lysophosphatidylinositol-acyltransferase-1 (LPIAT1) is required to maintain physiological levels of PtdIns and PtdInsP(2) in the mouse. PLOS ONE 8, e58425.

101. Andreyev AY, Fahy E, Guan Z, et al. (2010) Subcellular organelle lipidomics in TLR-4-activated macrophages. J Lipid Res 51, 2785-2797.

102. Shulga YV, Myers DS, Ivanova PT, et al. (2010) Molecular species of phosphatidylinositol-cycle intermediates in the endoplasmic reticulum and plasma membrane. Biochemistry 49, 312-317.

103. Westrate LM, Lee JE, Prinz WA, et al. (2015) Form follows function: the importance of endoplasmic reticulum shape. Annu Rev Biochem 84, 791-811.
104. Nixon-Abell J, Obara CJ, Weigel AV, et al. (2016) Increased spatiotemporal resolution reveals highly dynamic dense tubular matrices in the peripheral ER. Science 354, pii: aaf3928.

105. Waugh MG, Minogue S, Clayton EL, et al. (2011) CDPdiacylglycerol phospholipid synthesis in detergent-soluble, non-raft, membrane microdomains of the endoplasmic reticulum. J Lipid Res 52, 2148-2158.

106. D'Souza K, Kim YJ, Balla T, et al. (2014) Distinct properties of the two isoforms of CDP-diacylglycerol synthase. Biochemistry 53, 7358-7367.

107 Bochud A \& Conzelmann A (2015) The active site of yeast phosphatidylinositol synthase Pis1 is facing the cytosol. Biochim Biophys Acta 1851, 629-640.

108 Kim YJ, Guzman-Hernandez ML \& Balla T (2011) A highly dynamic ER-derived phosphatidylinositol-synthesizing organelle supplies phosphoinositides to cellular membranes. Dev Cell 21, 813--8824.

109. Kim YJ, Guzman-Hernandez ML \& Balla T (2013) Inositol lipid regulation of lipid transfer in specialized membrane domains. Trends Cell Biol 23, 270-278.

110. Nishimura T, Tamura N, Kono N, et al. (2017) Autophagosome formation is initiated at phosphatidylinositol synthaseenriched ER subdomains. EMBO J 36, 1719-1735.

111. English AR \& Voeltz GK (2013) Rab10 GTPase regulates ER dynamics and morphology. Nat Cell Biol 15, 169-178.

112. Bahmanyar S (2015) Spatial regulation of phospholipid synthesis within the nuclear envelope domain of the endoplasmic reticulum. Nucleus 6, 102-106.

113. D'Souza K \& Epand RM (2014) Enrichment of phosphatidylinositols with specific acyl chains. Biochim Biophys Acta 1838, 1501-1508.

114. Lee HC, Inoue T, Sasaki J, et al. (2012) LPIAT1 regulates arachidonic acid content in phosphatidylinositol and is required for cortical lamination in mice. Mol Biol Cell 23, $4689-4700$

115. Johansen A, Rosti RO, Musaev D, et al. (2016) Mutations in MBOAT7, encoding lysophosphatidylinositol acyltransferase I, lead to intellectual disability accompanied by epilepsy and autistic features. Am J Hum Genet 99, 912-916.

116. Mancina RM, Dongiovanni P, Petta S, et al. (2016) The MBOAT7-TMC4 Variant rs641738 increases risk of nonalcoholic fatty liver disease in individuals of European descent. Gastroenterology 150, 1219-1230.

117. Luukkonen PK, Zhou Y, Hyötyläinen T, et al. (2016) The MBOAT7 variant rs641738 alters hepatic phosphatidylinositols and increases severity of non-alcoholic fatty liver disease in humans. J Hepatol 65, 1263-1265.

118. Thabet K, Asimakopoulos A, Shojaei M, et al. (2016) MBOAT7 rs641738 increases risk of liver inflammation and transition to fibrosis in chronic hepatitis C. Nat Commun 7, 12757 .

119. Eslam M, Valenti L \& Romeo S (2018) Genetics and epigenetics of NAFLD and NASH: clinical impact. $J$ Hepatol $\mathbf{6 8}$, 268-279.

120 Kinoshita T, Maeda Y \& Fujita M (2013) Transport of glycosylphosphatidylinositol-anchored proteins from the endoplasmic reticulum. Biochim Biophys Acta 1833, 2473-2478.

121. Chedid A \& Nair V (1972) Diurnal rhythm in endoplasmic reticulum of rat liver: electron microscopic study. Science 175, 176-179.

122 Cretenet G, Le Clech M \& Gachon F (2010) Circadian clockcoordinated $12 \mathrm{hr}$ period rhythmic activation of the IRE1alpha pathway controls lipid metabolism in mouse liver. Cell Metab 11, 47-57. 
123. Bass J \& Takahashi JS (2010) Circadian integration of metabolism and energetics. Science 330, 1349-1354.

124. Soeda J, Cordero P, Li J, et al. (2017) Hepatic rhythmicity of endoplasmic reticulum stress is disrupted in perinatal and adult mice models of high-fat diet-induced obesity. Int J Food Sci Nutr 68, 455-466.

125. Fagone P \& Jackowski S (2009) Membrane phospholipid synthesis and endoplasmic reticulum function. J Lipid Res $\mathbf{5 0}$, Suppl., S311-S316.

126. Snapp EL, Hegde RS, Francolini M, et al. (2003) Formation of stacked ER cisternae by low affinity protein interactions. J Cell Biol 163, 257-269.

127. Ferrero S, Grados-Torrez RE, Leivar P, et al. (2015) Proliferation and morphogenesis of the endoplasmic reticulum driven by the membrane domain of 3-hydroxy-3methylglutaryl Coenzyme A reductase in plant cells. Plant Physiol 168, 899-914.

128. Christodoulou A, Santarella-Mellwig R, Santama N, et al. (2016) Transmembrane protein TMEM170A is a newly discovered regulator of ER and nuclear envelope morphogenesis in human cells. J Cell Sci 129, 1552-1565.

129. Sriburi R, Bommiasamy H, Buldak GL, et al. (2007) Coordinate regulation of phospholipid biosynthesis and secretory pathway gene expression in XBP-1(S)-induced endoplasmic reticulum biogenesis. J Biol Chem 282, 7024-7034.

130. Bommiasamy H, Back SH, Fagone P, et al. (2009) ATF6alpha induces XBP1-independent expansion of the endoplasmic reticulum. J Cell Sci 122, 1626-1636.

131. Lagace TA \& Ridgway ND (2013) The role of phospholipids in the biological activity and structure of the endoplasmic reticulum. Biochim Biophys Acta 1833, 2499-2510.

132. Covino R, Ballweg S, Stordeur C, et al. (2016) A eukaryotic sensor for membrane lipid saturation. Mol Cell 63, 49-59.

133. Takewaka T, Zimmer T, Hirata A, et al. (1999) Null mutation in IRE1 gene inhibits overproduction of microsomal cytochrome P450Alk1 (CYP 52A3) and proliferation of the endoplasmic reticulum in Saccharomyces cerevisiae. J Biochem 125, 507-514.

134. Schuck S, Prinz WA, Thorn KS, et al. (2009) Membrane expansion alleviates endoplasmic reticulum stress independently of the unfolded protein response. J Cell Biol 187, 525-536.

135. Maiuolo J, Bulotta S, Verderio C, et al. (2011) Selective activation of the transcription factor ATF6 mediates endoplasmic reticulum proliferation triggered by a membrane protein. Proc Natl Acad Sci USA 108, 7832-7837.

136. Promlek T, Ishiwata-Kimata Y, Shido M, et al. (2011) Membrane aberrancy and unfolded proteins activate the endoplasmic reticulum stress sensor Ire1 in different ways. Mol Biol Cell 22, 3520-3532.

137. Volmer R, van der Ploeg K \& Ron D (2013) Membrane lipid saturation activates endoplasmic reticulum unfolded protein response transducers through their transmembrane domains. Proc Natl Acad Sci U S A 110, 4628-4633.

138. Masuda M, Miyazaki-Anzai S, Keenan AL, et al. (2015) Saturated phosphatidic acids mediate saturated fatty acidinduced vascular calcification and lipotoxicity. J Clin Invest 125, 4544-4558.

139. Halbleib K, Pesek K, Covino R, et al. (2017) Activation of the unfolded protein response by lipid bilayer stress. Mol Cell 67, 673-684.

140. Kono N, Amin-Wetzel N \& Ron D (2017) Generic membranespanning features endow IRE1 $\alpha$ with responsiveness to membrane aberrancy. Mol Biol Cell 28, 2318-2332.

141. Holthuis JC \& Menon AK (2014) Lipid landscapes and pipelines in membrane homeostasis. Nature 510, 48-57.
142. Birner R, Bürgermeister M, Schneiter R, et al. (2001) Roles of phosphatidylethanolamine and of its several biosynthetic pathways in Saccharomyces cerevisiae. Mol Biol Cell 12, 997-1007.

143. Van der Veen JN, Kennelly JP, Wan S, et al. (2017) The critical role of phosphatidylcholine and phosphatidylethanolamine metabolism in health and disease. Biochim Biophys Acta 1859, 1558-1572.

144. Stefan CJ, Trimble WS, Grinstein S, et al. (2017) Membrane dynamics and organelle biogenesis-lipid pipelines and vesicular carriers. BMC Biology 15, 102.

145. Wong LH, Čopič A \& Levine TP (2017) Advances on the transfer of lipids by lipid transfer proteins. Trends Biochem Sci 42, 516-530.

146. French PJ, Bunce CM, Stephens LR, et al. (1991) Changes in the levels of inositol lipids and phosphates during the differentiation of HL60 promyelocytic cells towards neutrophils or monocytes. Proc Roy Soc B 245, 193-201.

147. Fagone P, Sriburi R, Ward-Chapman C, et al. (2007) Phospholipid biosynthesis program underlying membrane expansion during B-lymphocyte differentiation. J Biol Chem 282, 7591-7605.

148. Kirk SJ, Cliff JM, Thomas JA, et al. (2010) Biogenesis of secretory organelles during B cell differentiation. J Leukoc Biol 87, 245-255.

149. Kakazu E, Mauer AS, Yin M, et al. (2016) Hepatocytes release ceramide-enriched pro-inflammatory extracellular vesicles in an IRE1 $\alpha$-dependent manner. J Lipid Res 57, 233-245.

150. Croze ML, Géloën A \& Soulage CO (2015) Abnormalities in myo-inositol metabolism associated with type 2 diabetes in mice fed a high-fat diet: benefits of a dietary myo-inositol supplementation. Br J Nutr 113, 1862-1875.

151. Davis KR, Giesy SL, Long Q, et al. (2016) XBP1 Regulates the biosynthetic capacity of the mammary gland during lactation by controlling epithelial expansion and endoplasmic reticulum formation. Endocrinology 157, 417-428.

152. Hasegawa D, Calvo V, Avivar-Valderas A, et al. (2015) Epithelial Xbp1 is required for cellular proliferation and differentiation during mammary gland development. Mol Cell Biol 35, 1543-1556

153. Oza-Frank R \& Gunderson EP (2017) In-hospital breastfeeding experiences among women with gestational diabetes. Breastfeed Med 12, 261-268.

154. Gunderson EP, Hurston SR, Ning X, et al. (2015) Lactation and progression to Type 2 diabetes mellitus after gestational diabetes mellitus: a prospective cohort study. Ann Intern Med 163, 889-898.

155. Bahmanyar S, Biggs R, Schuh AL, et al. (2014) Spatial control of phospholipid flux restricts endoplasmic reticulum sheet formation to allow nuclear envelope breakdown. Genes Dev 28, 121-126.

156. Paul C, Laganà AS, Maniglio P, et al. (2016) Inositol's and other nutraceuticals' synergistic actions counteract insulin resistance in polycystic ovarian syndrome and metabolic syndrome: state-of-the-art and future perspectives. Gynecol Endocrinol 32, 431-438.

157. Pundir J, Psaroudakis D, Savnur P, et al. (2018) Inositol treatment of anovulation in women with polycystic ovary syndrome: a meta-analysis of randomised trials. BJOG 125, 299-308.

158. Calogero AE, Gullo G, La Vignera S, et al. (2015) Myoinositol improves sperm parameters and serum reproductive hormones in patients with idiopathic infertility: a prospective double-blind randomized placebo-controlled study. Andrology 3, 491-495. 
159. Gulino FA, Leonardi E, Marilli I, et al. (2016) Effect of treatment with myo-inositol on semen parameters of patients undergoing an IVF cycle: in vivo study. Gynecol Endocrinol 32, 65-68.

160. Capece M, Romeo G, Ruffo A, et al. (2017) A phytotherapic approach to reduce sperm DNA fragmentation in patients with male infertility. Urologia 84, 79-82.

161. Palmieri M, Papale P, Della Ragione A, et al. (2016) In vitro antioxidant treatment of semen samples in assisted reproductive technology: effects of myo-inositol on nemaspermic parameters. Int J Endocrinol 2016, 2839041.

162. Montanino Oliva M, Minutolo E, Lippa A, et al. (2016) Effect of myoinositol and antioxidants on sperm quality in men with metabolic syndrome. Int J Endocrinol 2016, 1674950.

163. Montanino Oliva M, Poverini R, Lisi R, et al. (2016) Treating woman with myo-inositol vaginal suppositories improves partner's sperm motility and fertility. Int J Endocrinol 2016, 7621942

164. Korosi T, Barta C, Rokob K, et al. (2017) Physiological Intra-Cytoplasmic Sperm Injection (PICSI) outcomes after oral pretreatment and semen incubation with myo-inositol in oligoasthenoteratozoospermic men: results from a prospective, randomized controlled trial. Eur Rev Med Pharmacol Sci 21, 2 Suppl., 66-72.

165. Dinkova A, Martinov D \& Konova E (2017) Efficacy of myoinositol in the clinical management of patients with asthenozoospermia. Eur Rev Med Pharmacol Sci 21, 2 Suppl., 62-65.

166. Chiu TT, Rogers MS, Law EL, et al. (2002) Follicular fluid and serum concentrations of myo-inositol in patients undergoing IVF: relationship with oocyte quality. Hum Reprod 17, 1591-1596.

167. Brusco GF \& Mariani M (2013) Inositol: effects on oocyte quality in patients undergoing ICSI. An open study. Eur Rev Med Pharmacol Sci 17, 3095-3102.

168. Bevilacqua A, Carlomagno G, Gerli S, et al. (2015) Results from the International Consensus Conference on myo-inositol and D-chiro-inositol in obstetrics and gynecology - assisted reproduction technology. Gynecol Endocrinol 31, 441-446.

169. Vitale SG, Rossetti P, Corrado F, et al. (2016) How to achieve high-quality oocytes? The key role of myo-inositol and melatonin. Int J Endocrinol 2016, 4987436.

170. Wdowiak A (2016) Myoinositol improves embryo development in PCOS patients undergoing ICSI. Int J Endocrinol 2016, 6273298.

171. Simi G, Genazzani AR, Obino ME, et al. (2017) Inositol and in vitro fertilization with embryo transfer. Int J Endocrinol 2017, 5469409 .

172. Minozzi M, Nordio M \& Pajalich R (2013) The combined therapy myo-inositol plus D-chiro-inositol, in a physiological ratio, reduces the cardiovascular risk by improving the lipid profile in PCOS patients. Eur Rev Med Pharmacol Sci 17, 537-5540.

173. Kamenov Z, Kolarov G, Gateva A, et al. (2015) Ovulation induction with myo-inositol alone and in combination with clomiphene citrate in polycystic ovarian syndrome patients with insulin resistance. Gynecol Endocrinol 31, 131-135.

174. Unfer V, Nestler JE, Kamenov ZA, et al. (2016) Effects of inositol(s) in women with PCOS: a systematic review of randomized controlled trials. Int J Endocrinol 2016, 1849162.

175. Genazzani AD (2016) Inositol as putative integrative treatment for PCOS. Reprod Biomed Online 33, 770-780.

176. Benelli E, Del Ghianda S, Di Cosmo C, et al. (2016) A combined therapy with myo-inositol and D-chiro-inositol improves endocrine parameters and insulin resistance in PCOS young overweight women. Int J Endocrinol 2016, 3204083.
177. Laganà AS, Rossetti $\mathrm{P}$, Buscema $\mathrm{M}$, et al. (2016) Metabolism and ovarian function in PCOS women: a therapeutic approach with inositols. Int J Endocrinol 2016, 6306410.

178. Pkhaladze L, Barbakadze L \& Kvashilava N (2016) Myoinositol in the treatment of teenagers affected by PCOS. Int J Endocrinol 2016, 1473612.

179. Fruzzetti F, Perini D, Russo M, et al. (2017) Comparison of two insulin sensitizers, metformin and myo-inositol, in women with polycystic ovary syndrome (PCOS). Gynecol Endocrinol 33, 39-42.

180. Crawford TJ, Crowther CA, Alsweiler J, et al. (2015) Antenatal dietary supplementation with myo-inositol in women during pregnancy for preventing gestational diabetes. The Cochrane Database of Systematic Reviews 2015, issue 12, CD011507.

181. Brown J, Crawford TJ, Alsweiler J, et al. (2016) Dietary supplementation with myo-inositol in women during pregnancy for treating gestational diabetes. The Cochrane Database of Systematic Reviews 2016, issue 9, CD012048.

182. Matarrelli B, Vitacolonna E, D'Angelo M, et al. (2013) Effect of dietary myo-inositol supplementation in pregnancy on the incidence of maternal gestational diabetes mellitus and fetal outcomes: a randomized controlled trial. J Matern Fetal Neonatal Med 26, 967-972.

183. Gugliani E, Cagnazzo E, Gugliano B, et al. (2013) The prevention of gestational diabetes. J Diabetes Metab 4, 7 .

184. D’Anna R, Di Benedetto A, Scilipoti A, et al. (2015) Myo-inositol supplementation for prevention of gestational diabetes in obese pregnant women: a randomized controlled trial. Obstet Gynecol 126, 310-315.

185. Rogozińska E, Chamillard M, Hitman GA, et al. (2015) Nutritional manipulation for the primary prevention of gestational diabetes mellitus: a meta-analysis of randomised studies. PLOS ONE 10, e0115526.

186. Celentano C, Matarrelli B, Mattei PA, et al. (2016) Myoinositol supplementation to prevent gestational diabetes mellitus. Curr Diab Rep 16, 30.

187. Lubin V, Shojai R, Darmon P, et al. (2016) A pilot study of gestational diabetes mellitus not controlled by diet alone: first-line medical treatment with myoinositol may limit the need for insulin. Diabetes Metab 42, 192-195.

188. Farren M, Daly N, McKeating A, et al. (2017) The prevention of gestational diabetes mellitus with antenatal oral inositol supplementation: a randomized controlled trial. Diabetes Care 40, 759-763.

189. Maeba R, Hara H, Ishikawa H, et al. (2008) Myo-inositol treatment increases serum plasmalogens and decreases small dense LDL, particularly in hyperlipidemic subjects with metabolic syndrome. J Nutr Sci Vitaminol (Tokyo) $5 \mathbf{4}$, 196-202.

190. Giordano D, Corrado F, Santamaria A, et al. (2011) Effects of myo-inositol supplementation in postmenopausal women with metabolic syndrome: a perspective, randomized, placebo-controlled study. Menopause 18, 102-104.

191. Santamaria A, Giordano D, Corrado F, et al. (2012) One-year effects of myo-inositol supplementation in postmenopausal women with metabolic syndrome. Climacteric 15, 490-495.

192. Capasso I, Esposito E, Maurea N, et al. (2013) Combination of inositol and alpha lipoic acid in metabolic syndrome-affected women: a randomized placebo-controlled trial. Trials 14, 273

193. Ferrari F, Facchinetti F, Ontiveros AE, et al. (2016) The effect of combined inositol supplementation on maternal metabolic profile in pregnancies complicated by metabolic syndrome and obesity. Am J Obstet Gynecol 215, e1-e8. 
194. Nas K \& Tưú L (2017) A comparative study between myoinositol and metformin in the treatment of insulinresistant women. Eur Rev Med Pharmacol Sci 21, 2 Suppl., 77-82.

195. Pintaudi B, Di Vieste G \& Bonomo M (2016) The Effectiveness of myo-inositol and D-chiro inositol treatment in Type 2 diabetes. Int J Endocrinol 2016, 9132052.

196. Greene NDE, Leung KY, Gay V, et al. (2016) Inositol for the prevention of neural tube defects: a pilot randomised controlled trial. Brit J Nutr 115, 974-983.

197. Howlett A, Ohlsson A \& Plakkal N (2015) Inositol in preterm infants at risk for or having respiratory distress syndrome.
The Cochrane Database of Systematic Reviews 2015, CD000366 (Epublication ahead of print version).

198. Phelps DL, Ward RM, Williams RL, et al. (2016) Safety and pharmacokinetics of multiple dose myo-inositol in preterm infants. Pediatr Res 80, 209-217.

199. Nordio M \& Basciani S (2017) Treatment with myo-Inositol and selenium ensures euthyroidism in patients with autoimmune thyroiditis. Int J Endocrinol 2017, 2549491.

200. Ferrari SM, Fallahi P, Di Bari F, et al. (2017) Myo-inositol and selenium reduce the risk of developing overt hypothyroidism in patients with autoimmune thyroiditis. Eur Rev Med Pharmacol Sci 21, 2 Suppl., 36-42. 